\title{
BMJ Open Perceptions of the functioning and effectiveness of nursing regulators in Ghana and South Africa: a cross- sectional study
}

\author{
Christmal Dela Christmals (D) , ${ }^{1}$ Lydia Aziato (D) , ${ }^{2}$ Laetitia Charmaine Rispel (D) ${ }^{1}$
}

To cite: Christmals CD, Aziato L, Rispel LC. Perceptions of the functioning and effectiveness of nursing regulators in Ghana and South Africa: a crosssectional study. BMJ Open 2021;11:e050580. doi:10.1136/ bmjopen-2021-050580

- Prepublication history and additional supplemental material for this paper are available online. To view these files, please visit the journal online (http://dx.doi.org/10.1136/ bmjopen-2021-050580)

Received 23 February 2021 Accepted 02 November 2021

Check for updates

(c) Author(s) (or their employer(s)) 2022. Re-use permitted under CC BY-NC. No commercial re-use. See rights and permissions. Published by BMJ.

${ }^{1}$ SARChl Chair: Research on the Health Workforce for Equity and Quality, Centre for Health Policy, School of Public Health, University of the Witwatersrand, Johannesburg-Braamfontein, Gauteng, South Africa

${ }^{2}$ Adult Health, University of Ghana College of Health Sciences, Accra, Ghana

Correspondence to Christmal Dela Christmals; christmal.christmals@wits.ac.za

\section{ABSTRACT}

Objective Nursing regulators are important governance structures for nurses who are critical to the achievement of universal health coverage (UHC). This study examined the perspectives of the heads of nursing education institutions (NEIs) in Ghana and South Africa on the functioning and effectiveness of the respective nursing regulators.

Design This was a cross-sectional survey.

Setting This study was conducted in Ghana and South Africa

Participants Heads of accredited NEls in Ghana $(n=65)$ and in South Africa $(\mathrm{n}=39)$.

Results In South Africa, the mean score for overall functioning of the South African Nursing Council (SANC) was 4.6 (SD 1.97), whereas the mean score for overall functioning of the Nursing and Midwifery Council of Ghana (N\&MC) was 7.1 (SD 1.7) $(p<0.0001)$. Similarly, the mean score for effectiveness of the SANC by NEls was 5.1, compared with the mean effectiveness score of 7.2 for the $N \& M C(p<0.001)$

Compared to the SANC, the heads of NEls scored the N\&MC higher on each of the six functional areas of policy-making (Ghana=7.06; $\mathrm{SA}=4.56$ ); accreditation (Ghana $=7.40 ; S A=4.10$ ) legal and disciplinary actions (Ghana $=6.45 ; \mathrm{SA}=5.52$ ); examination (Ghana $=7.84$; $\mathrm{SA}=5.00$ ); registration (Ghana $=8.27$; $\mathrm{SA}=5.96$ ) and communication and transparency (Ghana $=6.87 ; \mathrm{SA}=6.05$ ). Conclusion Both the N\&MC and SANC are wellestablished regulators and are vital to ensure that the nursing workforce in each country is able to deliver quality healthcare, thereby contributing to UHC and population health improvements. However, the study findings suggest the need for concerted efforts to improve the functioning and effectiveness of the regulators, especially the SANC. The six functional areas could guide the necessary improvements in regulator functioning and effectiveness, in partnership with relevant stakeholders.

\section{INTRODUCTION}

The COVID-19 pandemic has demonstrated the importance of the nursing workforce in providing health services during emergencies, and in achieving universal health coverage (UHC). ${ }^{1}{ }^{2}$ Health system governance is critical to the strengthening of the nursing workforce. ${ }^{1}$ The WHO defines health
Strengths and limitations of this study

- The main strength of the study is the novel comparison of the perceptions of the heads of nursing education institutions on the functioning and effectiveness of the nursing regulators in Ghana and South Africa.

- This study provides empirical evidence on the perceived functioning and effectiveness of the nursing regulators in Ghana and South Africa.

- The study offers a baseline to monitor changes or improvements over time in nursing education institution perceptions of the nurse regulator in each country.

- This is one of the first comparative nursing governance studies in sub-Saharan Africa.

- The study is limited by its cross-sectional nature, providing the perspectives of key health policy actors at a point in time.

system governance as a wide range of stewardship and rule-making functions, that includes the regulation of healthcare providers. ${ }^{3}$ Globally, governance weaknesses contribute to poor performance of the health system and wastage in healthcare expenditure. ${ }^{4}$ Hence, one of the key objectives of 2030 Health Workforce Strategy of the WHO is to build the capacity of institutions for effective human resources for health governance. ${ }^{4}$ The 2020 State of the World's Nursing Report underscores the salience of the professional regulation of nurses and midwives. ${ }^{1}$ Regulation is important to ensure that nursing workforce can deliver safe, quality healthcare, ${ }^{5}$ thereby protecting the health of the public. ${ }^{6}$

Ghana $^{7-9}$ and South Africa ${ }^{10-12}$ have embarked on ambitious UHC reforms, which entail the implementation of national health insurance (NHI) systems, although of different forms and stages of implementation. In both countries, nurses constitute the majority of health professionals, and they play a critical role in ensuring that the health 
systems meet the goals of responsiveness, and improved population health outcomes. ${ }^{13} 14$ Both countries have nursing regulators established by law, and regulation has become institutionalised, reflecting the maturity of these councils. ${ }^{15}$ In Ghana, the Nursing and Midwifery Council (N\&MC) was established in $1971,{ }^{16}$ whereas the South African Nursing Council (SANC) was established in 1944 in South Africa. ${ }^{17}$ The mandate of these nursing councils is to protect the public, through regulating nursing education and practice. Both councils fulfil the seven core regulatory functions enunciated in the regulatory function framework. ${ }^{18}$ These functions are nursing and midwifery legislation; accreditation of preservice education; existing registration system and the use of registration data; licensure process; scope of practice; continuing professional development and professional misconduct and disciplinary powers. ${ }^{16-19}$ Both councils play a critical role in ensuring quality-nursing education through the accreditation of preservice education, the licensure process and the scope of practice regulations, ${ }^{16}{ }^{17}$ which in turn play an important role in providing high-quality care. Hence, the functioning and effectiveness of nursing councils as regulators are essential to fulfilling their legislated mandates.

In this study, nursing council functioning refers to the extent to which these structures fulfil the purpose or tasks enshrined in relevant legislation, whereas effectiveness refers to the degree to which the nursing councils are successful in producing desired results, that is, competent nursing practitioners able to provide high-quality care..$^{2021}$ For the sake of simplicity, the term nurse includes all categories of nurses and all midwives.

There is a large and diverse body of literature on the development or transformation of nursing legislation, ${ }^{22-28}$ regulatory reforms ${ }^{529}$ and the application of models or frameworks to strengthen regulation and/ or the regulator. ${ }^{183031}$ The 2020 State of Nursing report found that $86 \%$ of WHO member countries have a structure (eg, council or board) responsible for nursing regulation. ${ }^{1}$ However, these structures experience challenges of updated regulations and nursing workforce registries and suboptimal functioning. ${ }^{1}$ A 4-year evaluation of the African Health Profession Regulatory Collaborative for Nursing and Midwifery, which focused on nursing regulation to enable the provision of HIV services to pregnant women and children, found that the 17 targeted countries in East, Central and Southern Africa reported strengthened national regulatory frameworks. ${ }^{5}$ These countries also reported improvements in teamwork, improved collaboration and networking, and ability to obtain additional resources. ${ }^{5}$ However, the evaluation was based on self-reported group information by the grantees, that included the relevant councils. ${ }^{5}$ In addition, the evaluation was conducted by researchers who were intimately involved in obtaining and disbursing the grants. ${ }^{5}$

We could not find any published studies that have examined the functioning and/or effectiveness of the N\&MC in Ghana. In South Africa, the only published study we could find was the 1994 postal survey by Uys to determine the views of key nursing policy actors on the composition, functioning and stakeholder relationships of the SANC, and the apartheid established homeland nursing councils. $^{32}$ The study obtained a $42 \%$ response rate, and found an overall neutral attitude towards the councils. ${ }^{32}$ Respondents reported objections against the process of electing members and of developing regulations, and the people involved in disciplinary hearings. ${ }^{32}$ Although useful information was obtained, Uys' study is dated, predating democratic transformation of the SANC.

We conducted this study to examine the perceptions of the heads of nursing education institutions (NEIs) on the functioning and effectiveness of nursing councils in Ghana and South Africa. The study is important in light of the knowledge gaps on council functioning and effectiveness, the global imperative of UHC and the role of nursing regulators in enabling the delivery of safe, high-quality healthcare services relevant to the needs of populations.

\section{METHODS \\ Design}

This was a cross-sectional study conducted between 2018 and 2019.

\section{Settings}

The study was conducted in Ghana and South Africa. The two countries were selected purposively, for several reasons: location of the research team and their established relationships with the leadership of the nursing governance structures (including the Nursing Councils, National Nursing Associations, the heads of NEIs and the office of the Chief Nursing Officer); budgetary and logistical considerations and the actual or planned implementation of the NHI systems in both countries.

\section{Patient and public involvement}

No patients involved.

\section{Study population and sampling}

The population of interest was the heads (principal or head of college or head or dean or nursing) of all accredited NEIs in Ghana $(n=118)$ and South Africa $(n=74)$. We assumed that the principal/head or dean had interactions with the regulator and therefore had in-depth knowledge of and/or experience on functioning and/ or effectiveness with the nursing regulator. ${ }^{33}$ These NEIs included the universe of nursing departments at universities and nursing colleges in both the public and private sectors in the two countries, hence no sampling was done.

\section{Development of the data collection instrument}

Following an extensive literature review, including the relevant legislation in the two countries, the research team developed a self-administered questionnaire (SAQ) according to the study objectives. The questionnaire was divided into five sections. Section 1 obtained 
participant demographic information (eight items). Section 2 collected information on the NEI (five items). Section 3 of the SAQ focused on the participants' perceptions of the council's functioning and effectiveness and was subdivided into six functional areas: policy-making; accreditation; legal and disciplinary action; examination; registration and communication and transparency (28 items). Each of these items was measured on a Likert scale that ranged from 1 (poor) to 10 (excellent).

The fourth section consisted of two questions on NEIs perceptions of the relevant council's overall functioning and overall effectiveness, on a scale of 1-10 (see online supplemental material). The last open-ended section provided participants with the opportunity to add additional comments, but this information is not presented in this paper.

A team of seven nursing and health system researchers reviewed the tool for face and content validity. The tool was pretested among a group of nursing educators from both countries for its applicability. Following the comments and inputs provided during the pilot study, the tool required minor revisions on the phrasing of some questions. The results of the pilot study were excluded from the main study.

\section{Data collection}

In South Africa, we obtained information on accredited NEIs from the SANC website. In, Ghana, we obtained the information from the head of health training institutions and the Conference of Heads of Health Training Institutions. We verified the information and compiled a consolidated database of heads of NEIs.

In both countries, following informed consent, the researchers requested each participant to complete an online SAQ on Research Electronic Data Capture (REDCap), ${ }^{34}$ a secure web-based system. The heads of NEIs who were unable to complete the online SAQ, were given the opportunity to complete the SAQ on a handheld device or use a paper copy. A final follow-up telephonic survey was administered to participants who did not respond to the online survey. Data collection occurred over a period of 12 months.

\section{Data analysis}

Following the closure of the survey, the research team imported the data from REDCap into STATA V.13 for analysis. The first step was to conduct Kaiser-MeyerOlkin (KMO) tests to measure factor analysis sampling adequacy. ${ }^{35}$ Higher KMO values are better and provide the overall measure of the shared variance between the items, indicating that the items are related yet provide unique information on the described factors. ${ }^{35}$ Generally, a KMO greater than 0.5 as found in this study is considered acceptable or satisfactory for factor analysis. ${ }^{36}$ This was followed by an exploratory factor analysis for each of the six functional areas of the nursing council.

The minimum/maximum ranking, mean, SD and the p-value for independent sample t-test (for a normally distributed items) and two-sample Wilcoxon rank-sum test (for items not normally distributed) were used to test any differences in the scores for the perceived functioning and effectiveness of the nursing council. We classified the perceived functioning scores, as follows: 1-2 poor; 3-4 below average; 5-6 Average; 7-8 good and 9-10 excellent.

\section{Validity and reliability}

Cronbach's alpha coefficients were computed to determine the reliability and coherence ${ }^{37}$ between the items developed to measure the functioning and effectiveness of the councils in the six functional areas. These were higher than 0.70 demonstrating internal consistency and reliability of the SAQ: policy-making $(\alpha=0.94)$; accreditation $(\alpha=0.89)$; legal and disciplinary action $(\alpha=0.95)$; examination $\quad(\alpha=0.71)$; registration $(\alpha=0.80)$; and communication and transparency $(\alpha=0.91)$.

Average factor loadings were calculated to test the convergent construct validity of the questionnaire. An average factor loading greater than 0.70 signifies convergent validity. The factor loadings were: policy-making (0.81); accreditation (0.82); legal and disciplinary action (0.89); examination (0.74); registration (0.79) and communication and transparency (0.73) were all higher than 0.70 , thus confirming that the items on the questionnaire measured the relevant constructs. ${ }^{38}$

\section{Ethical considerations}

In South Africa, we also obtained permission to conduct the study from the three private hospital groups, and the nine Provincial Departments of Health.

The research team complied with the Singapore Statement on Research Integrity. ${ }^{39}$ All study participants received a study information sheet, and provided signed informed consent. The research team upheld the ethical principles of voluntary participation, confidentiality, respect, anonymity and privacy throughout the study.

\section{RESULTS}

\section{Participant characteristics}

We achieved a response rate of $55.2 \%(65 / 118)$ for NEIs in Ghana and 52.7\% (39/74) for NEIs in South Africa.

Table 1 shows the demographic and background characteristics of the study participants.

In both countries, the majority of the heads of NEIs were women (Ghana $=60 \%$; SA=92\%), although more men were in leadership positions in Ghana (35.3\%) compared with South Africa (7.7\%). The mean age of participants in Ghana was 50.4 years (range 35-65) and 54.4 years in South Africa (range 43-67). In both countries, a higher proportion of public nursing colleges participated in the study, although $73.8 \%$ of participants in Ghana were from public colleges, compared with $35.9 \%$ in South Africa. The majority of the study participants were in permanent positions (Ghana $=87.7 \%$; South Africa $=94.9 \%$ ).

On average, South African heads of NEIs had more work experience $(\pi=6.32$ years $)$ than those in Ghana 
Table 1 Demographic and background characteristics of study participants

\begin{tabular}{|c|c|c|c|c|}
\hline \multirow[b]{2}{*}{ Characteristic } & \multicolumn{2}{|c|}{ Ghana, n=65 } & \multicolumn{2}{|c|}{$\begin{array}{l}\text { South Africa, } \\
n=39\end{array}$} \\
\hline & Mean & SD & Mean & SD \\
\hline Age (mean) & 50.4 & 6.7 & 54.4 & 6.8 \\
\hline $\begin{array}{l}\text { Years of experience as Head of } \\
\text { Institution }\end{array}$ & 5.5 & 4.2 & 6.3 & 4.9 \\
\hline \multirow{2}{*}{$\begin{array}{l}\text { Years of experience as nurse } \\
\text { educator }\end{array}$} & 15.7 & 5.5 & 19.0 & 7.0 \\
\hline & $\mathbf{n}$ & $\%$ & $\mathbf{n}$ & $\%$ \\
\hline \multicolumn{5}{|l|}{ Gender } \\
\hline Female & 39 & 60.0 & 36 & 92.3 \\
\hline Male & 23 & 35.3 & 3 & 7.7 \\
\hline Unknown & 3 & 4.6 & - & - \\
\hline \multicolumn{5}{|l|}{ Type of institution } \\
\hline Public college & 48 & 73.8 & 14 & 35.9 \\
\hline Private college & 6 & 9.2 & 14 & 35.9 \\
\hline University & 11 & 16.9 & 11 & 28.2 \\
\hline \multicolumn{5}{|l|}{ Position } \\
\hline College Principal & 52 & 80.0 & 27 & 69.2 \\
\hline Head of Department & 11 & 16.9 & 9 & 23.1 \\
\hline Dean of Nursing School & 2 & 3.1 & 2 & 5.1 \\
\hline Unknown & - & - & 1 & 2.6 \\
\hline \multicolumn{5}{|l|}{ Nature of position } \\
\hline Permanent & 57 & 87.7 & 37 & 94.9 \\
\hline Acting & 6 & 9.2 & 2 & 5.1 \\
\hline Unknown & 2 & 3.1 & - & - \\
\hline
\end{tabular}

Registration as nurse educator

$\begin{array}{lrrrr}\text { Yes } & 57 & 87.7 & 38 & 97.4 \\ \text { No } & 6 & 9.2 & 0 & 0.0 \\ \text { Unknown } & 2 & 3.1 & 1 & 2.6\end{array}$

Programme offering (multiple answers possible)

\begin{tabular}{|lcccc}
\hline Degree & 16 & 13.8 & 10 & 15.4 \\
\hline Diploma & 54 & 46.6 & 17 & 26.2 \\
\hline Bridging course & 14 & 12.1 & 26 & 40.0 \\
\hline $\begin{array}{l}\text { Postbasic/graduate } \\
\text { Interaction with Council in preceding year }\end{array}$ & 2 & 1.7 & 12 & 18.5 \\
\hline Yes & 62 & 95.4 & 35 & 89.7 \\
\hline No & 3 & 4.6 & 3 & 7.7 \\
\hline Unknown & - & - & 1 & 2.6 \\
\hline Nature of interaction with Council (multiple answers possible) & \\
\hline Registration of students & 58 & 61.1 & 33 & 43.4 \\
\hline Accreditation & 31 & 32.6 & 30 & 39.5 \\
\hline Disciplinary process/action & 6 & 6.3 & 13 & 17.1 \\
\hline
\end{tabular}

$(\pi=5.52$ years). South Africans also had more experience as nurse educators than their Ghanaian counterparts: South Africa ( $\pi=19.03$ years) and Ghana ( $\pi=15.67$ years).

The heads of NEIs reported that the nursing education programmes being implemented included the diploma in nursing, bachelor's degree in nursing, bridging programmes (to train enrolled nurses to become professional nurses) and postgraduate degrees. The duration of the bridging programme from an enrolled nurse to a professional/general nurse is 2-3 years in Ghana and 2 years in South Africa. The duration of the diploma in nursing programme is 3 years in Ghana and 4 years in South Africa.

\section{Perceptions of NEls on the different functional areas of the regulator}

Table 2 presents the individual item scores for functioning of the nursing councils in Ghana and South Africa.

In the functional areas of policy-making; accreditation; examination and registration, the NEIs' scores for the $\mathrm{N \& MC}$ were in the category of average (5-6) or good (7-8), whereas the scores for the SANC were below average (3-4) or average (5-6). In these three functional areas, the NEIs in Ghana scored the N\&MC higher on all items compared with their South African counterparts. These differences were statistically significant. In the functional area of legal and disciplinary action, the NEIs scored the N\&MC and SANC similarly as average (5-6) on the items of investigating alleged transgressions, conducting hearings and taking appropriate disciplinary action.

In the functional areas of communication and transparency, the only item that SANC obtained a higher score compared with the GN\&MC was on the availability of the nursing register in the country $(\mathrm{p}=0.01)$. NEIs provided a similar score to the two councils for the item on the public availability of the names of NEIs (table 2). On all other items, NEIs in Ghana scored the N\&MC higher, compared with SANC, and these differences were statistically significant.

The overall mean scores for each of these functional areas are shown in figure 1, confirming that NEIs scored the N\&MC higher on each of these functional areas compared with the NEIs scores for SANC. For each of the functional areas, the difference between mean scores was statistically significant: policy-making $(\pi \mathrm{d}=2.51 ; \mathrm{p}<0.001)$; accreditation $(\pi \mathrm{d}=3.21 ; \mathrm{p}<0.001)$; legal and disciplinary actions $(\pi \mathrm{d}=0.93 ; \mathrm{p}=0.03)$; examination $(\pi \mathrm{d}=2.31$; $\mathrm{p}<0.001)$; registration $(\pi \mathrm{d}=251 ; \mathrm{p}<0.001)$ and communication and transparency $(\pi \mathrm{d}=0.82 ; \mathrm{p}=0.04)$.

\section{Perceptions of NEls on overall council functioning and effectiveness}

In South Africa, the mean score for overall functioning of the SANC was 4.6 (SD 1.97), whereas the mean score for overall functioning of the N\&MC in Ghana was 7.1 (SD 1.7). This difference was statistically significant $(p<0.0001)$. Similarly, the mean score for effectiveness of the SANC by NEIs was 5.1, compared with the mean effectiveness score of 7.2 for the N\&MC (table 3). This difference was also statistically significant $(p<0.001)$.

\section{DISCUSSION}

This was a novel, comparative study on the perceptions of NEIs on the functioning and effectiveness of the nursing regulators in Ghana and South Africa. Despite the 


\section{$\stackrel{+1}{\stackrel{+}{c}}$}

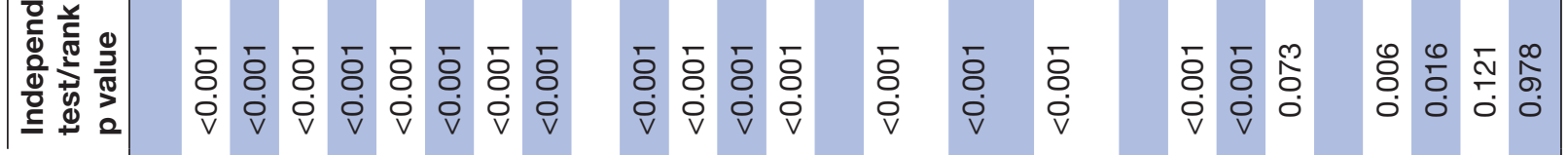

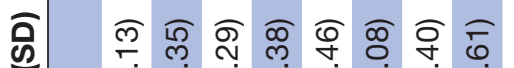

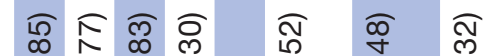

ชิ

वัฒ

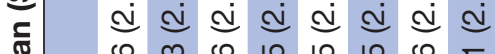

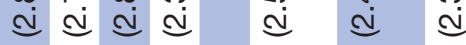

ㄴำ

ำ ำ

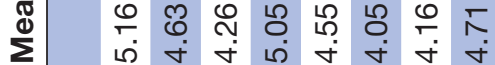

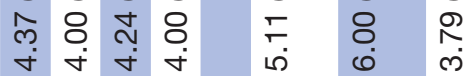

ग ले क

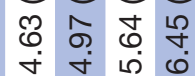

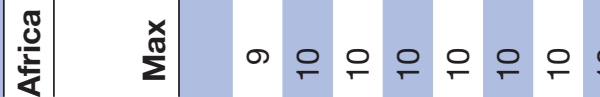

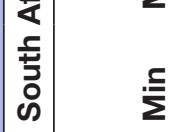

으 으 으 으 으 으 으

으 으 으 으 으 으 으

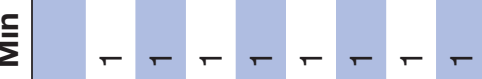

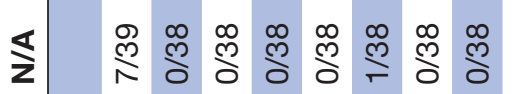

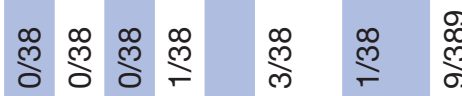

बิ

ठิ ఠ

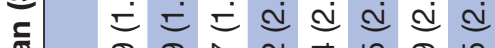

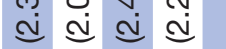

@i

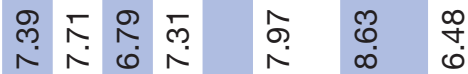

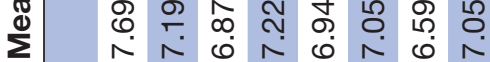

$\sum^{\times}$으 으 으 으 으 으으 우

은으으 으 으 으 으

으 으 으 으 으 으으

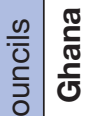
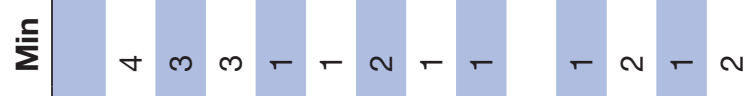

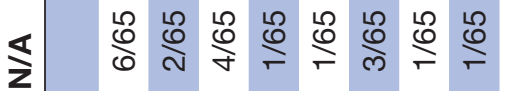

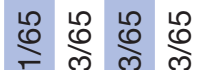

边

$\stackrel{1}{8}$

๒
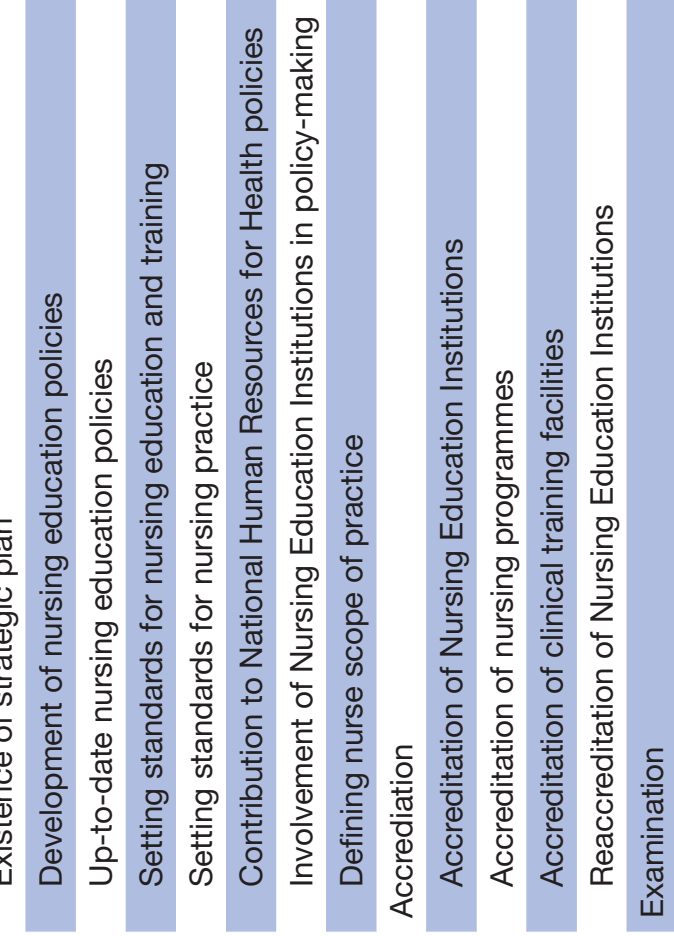

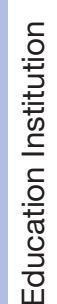

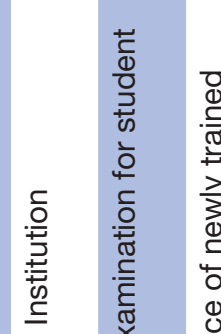

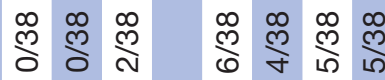

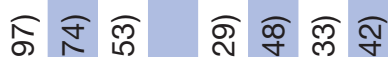

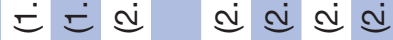

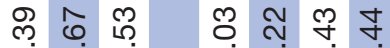
$\infty$ œ

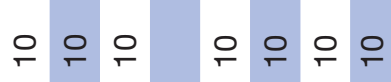




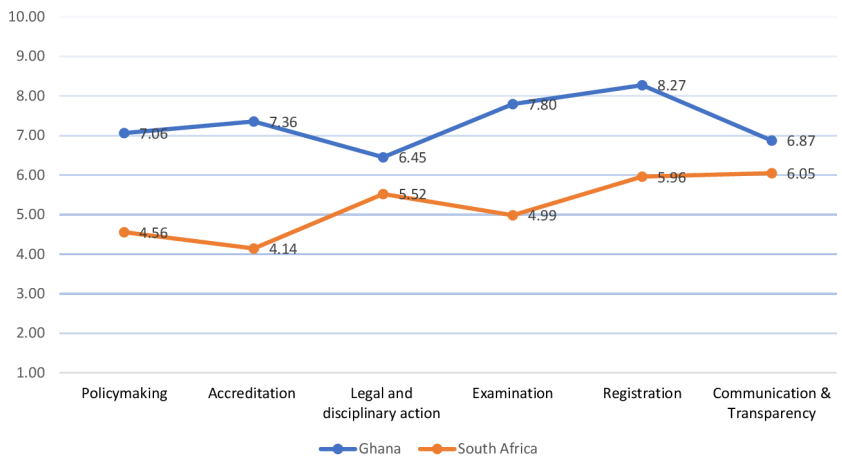

Figure 1 Mean rating of functional areas of the N\&MC and SANC. N\&MC, Nursing and Midwifery Council; SANC, South African Nursing Council

increasing emphasis on university-based nursing education in both countries, the majority of participants were from public nursing colleges, reflecting the dominant mode of professional nurse training. ${ }^{404}$

The heads of NEIs in South Africa scored the SANC below average for overall functioning (4.6) and average for effectiveness (5.1). In contrast, the heads of NEIs in Ghana scored the N\&MC 7.1 and 7.2 for overall functioning and effectiveness, respectively, which are good scores. There are several possible reasons for the differences in the overall mean scores for functioning and effectiveness between SANC and the GN\&MC. First, it could reflect the differences in the demographic characteristics of the study participants in the two countries. The South African participants had both more years of work experience and as nurse educators, and therefore had more experience of interacting with the relevant council. In South Africa, there were also more respondents from private NEIs. Second, Likert scales tend to be influenced by culture and/or the differences in geographical settings, ${ }^{42}{ }^{43}$ and hence could explain the different scores obtained for the two nursing regulators. Finally, the different scores might reflect the reality of SANC's functioning and effectiveness, as the regulator has been criticised previously for its dysfunctionality and suboptimal leadership. ${ }^{144}$

The functional area of policy-making measured eight items that ranged from the existence of a strategic plan to defining nurses' scopes of practice. NEIs in South Africa scored SANC below average for this functional area, and for the majority of items (table 2). These scores are not surprising as SANC has been criticised for the inertia and delays in the finalisation of nursing education reforms and scopes of practice. ${ }^{445}$ The N\&MC obtained a mean score of 7 , which could be due to its reform efforts in the preceding 5 years, including decentralisation to 10 regional offices and digitisation to improve service delivery. ${ }^{46}$ The heads of NEIs are key stakeholders in ensuring the production of a quality nursing workforce to achieve UHC and meet population health needs. ${ }^{1}$ One of the core mandates of N\&MC is to update and issue education and practice regulations to ensure the health 


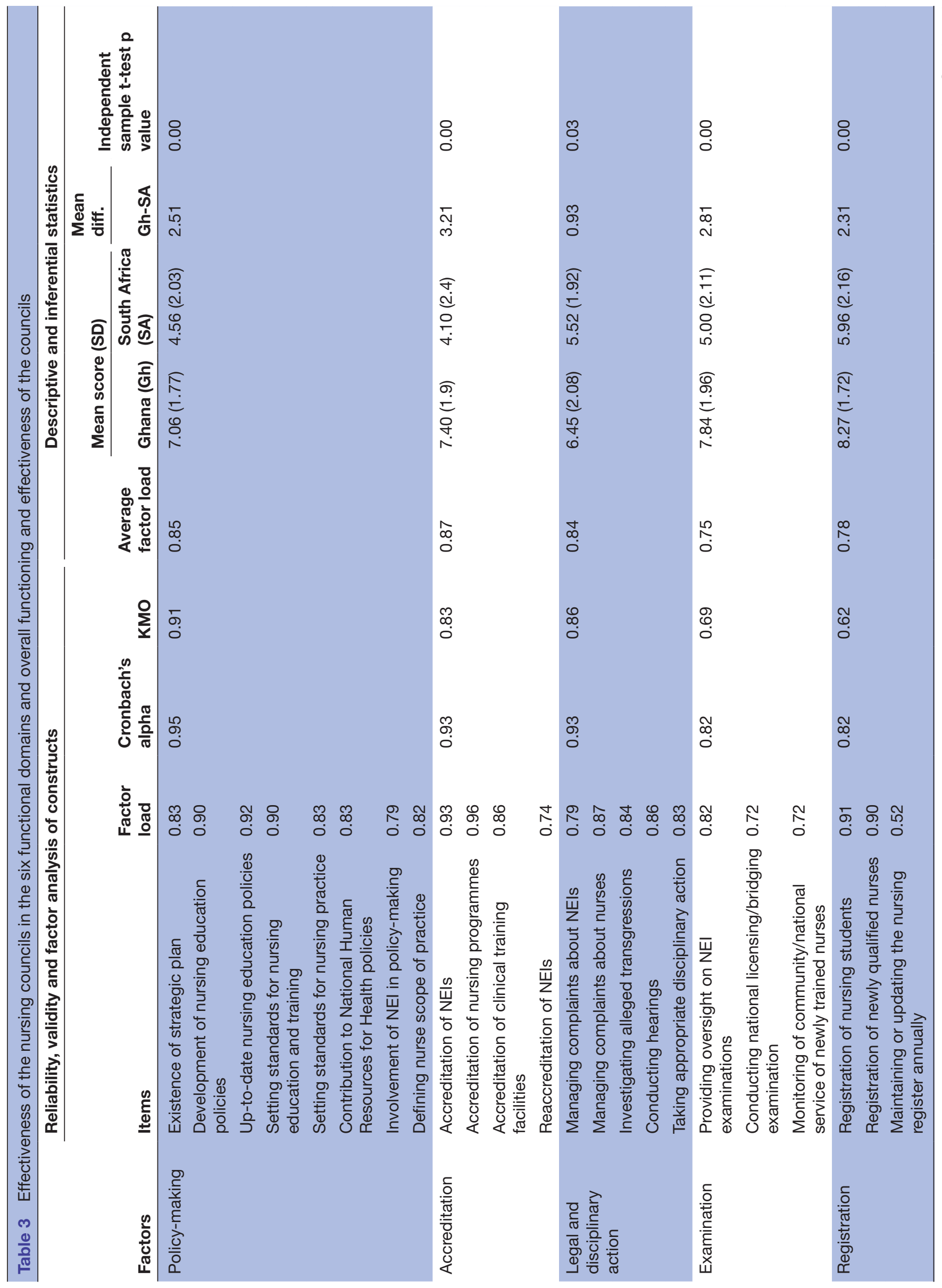




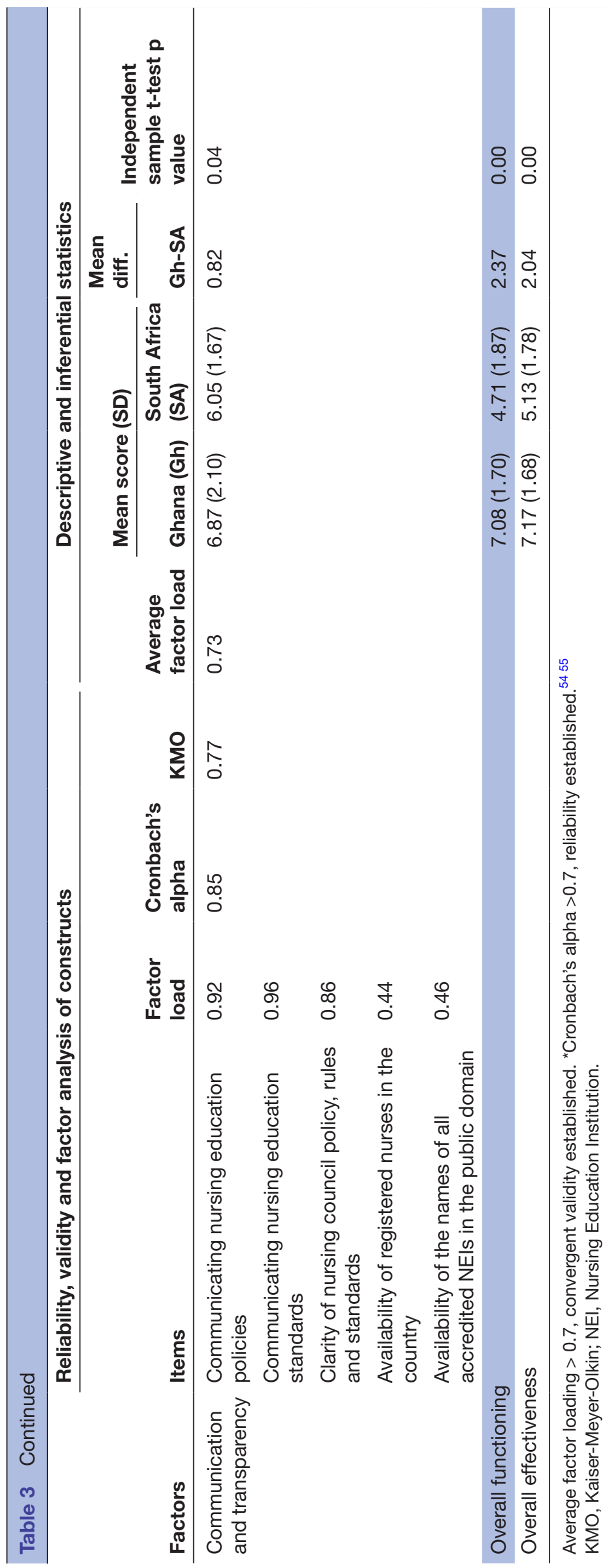

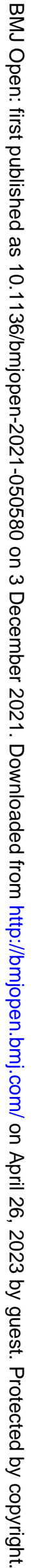


workforce is equipped to deliver safe, and high-quality healthcare. ${ }^{5} 1822$ Hence, it is incumbent on the SANC, and to a lesser extent the N\&MC to improve its policymaking function.

The study measured the accreditation of NEIs, nursing programmes, clinical training facilities, as well as reaccreditation. These are the core responsibilities of the heads of NEIs that require optimal functioning of the nursing council. The SANC obtained the lowest mean score of 4.10 , compared the score of 7.40 of the GN\&MC. The finding is not surprising as the SANC is overwhelmed with the phasing out of the legacy qualifications and phasing in of the new qualifications. ${ }^{45}$ A 2014 policy analysis study highlighted the slow progress in implementing nursing education reforms, weak governance by the SANC, insufficient commitment and poor planning for implementation. ${ }^{41}$ Evidence suggests that the situation remained largely unchanged in 2019 . $^{48}$

The functional area of examination measured oversight on examination by NEIs, conducting national examinations and monitoring of community or national service for newly trained nurses. SANC obtained an overall score of around 5 , while the score for the N\&MC was close to 8 . The item within the functional area that scored lowest was the monitoring of community service, which is compulsory in South Africa for newly qualified nurses. The differences in the scores for the two councils could be because of the perceptions of insufficient guidance from the SANC on community service for newly qualified professional nurses that was found in a South African province. ${ }^{49}$

The N\&MC obtained a good score of 8.27 for registration, which could reflect their efforts in using digital technology and creation of regional offices where nurses could register without having to travel to the head office. $^{46}{ }^{47}$ In contrast, the SANC obtained an average score of 5.96. Although SANC has implemented an alternative online registration to augment the onsite services provided, the low score could be due to the reported difficulties of NEIs and nurses with their registration. In addition, the Democratic Nursing Organisation of South Africa has protested again the SANC's decision to maintain centralised services, and refusal to establish regional offices. $^{50}$

Although the N\&MC obtained the lowest average score of 6.45 for the functional area of legal and disciplinary action, it was significantly higher than the SANC's average score of $5.52(\mathrm{p}=0.03)$. These average scores for both regulatory bodies suggest the need for improvements in this functional area. In light of the criticality of the nursing workforce, some scholars have recommended government resource allocation to nursing regulators to enable these institutions to fulfil their responsibilities. ${ }^{5152}$

The mandate of all regulatory bodies is to protect the public against harm. ${ }^{522}$ An essential aspect of regulation is the availability of the nursing register to the public and employers to verify the qualification and/or competence of nurses. The SANC obtained a significantly higher score
(6.44), compared with the N\&MC (4.85) on the availability of the nursing register to the public.

The average scores in the functional area of Communication and Transparency for both regulators suggest that greater efforts are needed, through inter alia institutional websites and the use of social media.

\section{STUDY LIMITATIONS AND STRENGTHS}

Despite extensive consultation and communication with stakeholders, we obtained response rates of $54 \%$ in Ghana, and $52 \%$ in South Africa. The cross-sectional nature of the study means that we obtained the perspectives of NEIs at a point in time, using a scoring system. Further research is needed to determine the qualitative reasons for the differences in the scores by the heads of NEIs. Future research should also complement the subjective scores through objective measures to assess council functioning and effectiveness.

There are several strengths of our study. We developed a robust tool to measure NEIs' perspectives of the functioning and effectiveness of the nursing regulators in Ghana and South Africa. The potential social desirability bias was minimised by using an SAQ. We obtained baseline data on perceived functioning and effectiveness, which could be used to monitor changes over time, and to compare with objective measures of regulator functioning and effectiveness.

The N\&MC obtained higher scores in all six functional areas than the SANC, suggesting perceptions of better functioning and effectiveness by the NEIs. However, there is need for continuous improvement in all functional areas of these nursing regulators. We could not find studies on similar initiatives as the $\mathrm{ARC}^{5}$ that provide a forum for nursing regulators to share experiences and learn from each other. For example, the N\&MC in Ghana introduced online licensing examination and established regional offices to enhance access and improve efficiency. ${ }^{53}$ Although a different context, SANC could learn from these experiences of the Ghana N\&MC. Furthermore, the WHO Africa regional office or the health desk of the African Union might provide appropriate forums for the sharing of good practices between or among nursing councils. This is important in light of the global goal of UHC, and the criticality of the nursing workforce to achieving this goal. ${ }^{14}$

\section{CONCLUSION}

Both the N\&MC and SANC are well-established regulators and are vital to ensure that the nursing workforce in each country is able to deliver quality healthcare, thereby contributing to UHC and population health improvements. The findings of this novel comparative study suggest that concerted efforts are needed to improve the functioning and effectiveness of the regulators, especially in South Africa. The six functional areas and 28 items could guide the necessary improvements in regulator 
functioning and effectiveness, in partnership with relevant stakeholders.

Acknowledgements We thank Drs Sue Armstrong and Prudence Ditlopo for comments on the data collection tool, and all the heads of the NEls for participating in the study. We will lalso ike to thank the Centre for Health Professions Education, North-West University for giving Christmal the time to work on this manauscript.

Contributors Study conceptualised by LCR and CDC; LCR, CDC and LA sought approval for the study; CDC collected data with the help of LA and LCR; CDC, LA and LCR analysed data and LCR, CDC and LA wrote the manuscript. All authors read and approved the final manuscript. CDC will act as the gaurantor.

Funding The South African Research Chair Initiative (SARChl) of the South African National Research Foundation funded this study (Grant \# 102219). The views expressed in this study are those of the authors.

Competing interests None declared.

Patient consent for publication Not required.

Ethics approval Ethical approval was obtained from the University of Witwatersrand Human Research Ethics Committee(\#M180977), and the Ghana Health Service Ethics Review Committee (\#GHS-ERC001/10/18).

Provenance and peer review Not commissioned; externally peer reviewed.

Data availability statement Data are available upon reasonable request. Data used for this study is stored at the Centre for Health Policy, School of Public Health, University of Witwatersrand and is available for sharing upon request.

Supplemental material This content has been supplied by the author(s). It has not been vetted by BMJ Publishing Group Limited (BMJ) and may not have been peer-reviewed. Any opinions or recommendations discussed are solely those of the author(s) and are not endorsed by BMJ. BMJ disclaims all liability and responsibility arising from any reliance placed on the content. Where the content includes any translated material, BMJ does not warrant the accuracy and reliability of the translations (including but not limited to local regulations, clinical guidelines, terminology, drug names and drug dosages), and is not responsible for any error and/or omissions arising from translation and adaptation or otherwise.

Open access This is an open access article distributed in accordance with the Creative Commons Attribution Non Commercial (CC BY-NC 4.0) license, which permits others to distribute, remix, adapt, build upon this work non-commercially, and license their derivative works on different terms, provided the original work is properly cited, appropriate credit is given, any changes made indicated, and the use is non-commercial. See: http://creativecommons.org/licenses/by-nc/4.0/.

\section{ORCID iDs}

Christmal Dela Christmals http://orcid.org/0000-0003-1811-0008

Lydia Aziato http://orcid.org/0000-0002-7813-5525

Laetitia Charmaine Rispel http://orcid.org/0000-0001-7806-6331

\section{REFERENCES}

1 WHO. The State of the World's Nursing 2020: investing in education, jobs and leadership. Geneva: World Health Organization (WHO), 2020.

2 Crisp N, Brownie S, Refsum C. Nursing and midwifery: the key to the rapid and cost-effective expansion of high-quality universal health coverage. Doha, Qatar: World Innovation Summit for Health, 2018.

3 WHO. Everybody's business. Strengthening health systems to improve health outcomes: WHO's framework for action. Geneva: World Health Organization, 2007.

4 WHO. Global strategy on human resources for health: workforce 2030. Geneva: World Health Organization (WHO), 2016.

5 Kelley MA, Spangler SA, Tison LI, et al. Promoting regulatory reform: the African health profession regulatory collaborative (ARC) for nursing and midwifery year 4 evaluation. J Nurs Regul 2017;8:41-52.

6 Jarosz L. Trends and challenges in regulating nursing practice: 10 years later. J Nurs Regul 2020;11:12-20.

7 Agyepong IA, Abankwah DNY, Abroso A, et al. The "Universal" in UHC and Ghana's National Health Insurance Scheme: policy and implementation challenges and dilemmas of a lower middle income country. BMC Health Serv Res 2016;16:504.

8 Alhassan RK, Nketiah-Amponsah E, Arhinful DK. A review of the National health insurance scheme in Ghana: what are the sustainability threats and prospects? PLoS One 2016;11:e0165151.
9 Fusheini A, Marnoch G, Gray AM. Stakeholders Perspectives on the Success Drivers in Ghana's National Health Insurance Scheme - Identifying Policy Translation Issues. Int J Health Policy Manag 2017;6:273-83.

10 Matsoso MP, Fryatt R. National Health Insurance: The first 18 months. In: Padarath A, English R, eds. South African health review 2012/13. Durban: Health Systems Trust, 2013.

$11 \mathrm{NDoH}$. National health insurance policy: towards universal health coverage. Pretoria, Republic of South Africa: National Department of Health (NDoH), 2017.

12 Zondi T, Day C. Measuring National Health Insurance: towards Universal Health Coverage in South Africa. In: Moeti T, Padarath A, eds. South African health review 2019. Durban: Health Systems Trust, 2019: 55-66.

13 Kwamie A, Asiamah M, Schaaf M, et al. Postings and transfers in the Ghanaian health system: a study of health workforce governance. Int J Equity Health 2017;16:85.

14 Rispel L, Bruce J. A profession in Peril: Revitalising nursing in South Africa. In: Padarath A, King J, English R, eds. South African health review 2014/15. Durban: Health Systems Trust, 2015: 117-26.

15 Howlett M, Newman J. After "the Regulatory Moment" in Comparative Regulatory Studies: Modeling the Early Stages of Regulatory Life Cycles. Journal of Comparative Policy Analysis: Research and Practice 2013;15:107-21.

16 Parliament of the Republic of Ghana. Health Professions Regulatory Bodies Act \#857 of 2013. Accra: Parliament, 2013: 38-53.

17 Republic of South Africa. Nursing act No. 33 of 2005. Pretoria: Government Printer, 2005.

18 McCarthy CF, Kelley MA, Verani AR, et al. Development of a framework to measure health profession regulation strengthening. Eval Program Plann 2014;46:17-24.

19 Christmals CD, Armstrong SJ. Curriculum framework for advanced practice nursing in sub-Saharan Africa: a multimethod study. BMJ Open 2020;10:e035580.

20 Ashraf G, Bte Abd Kadir S, Kadir SA. A Review on the Models of Organizational Effectiveness: A Look at Cameron's Model in Higher Education. International Education Studies 2012;5:80-7.

21 Price JL. Handbook of organizational measurement. Int J Manpow 1997;18:305-558.

22 Benton DC, González-Jurado MA, Beneit-Montesinos JV. Professional regulation, public protection and nurse migration. Collegian 2014;21:53-9.

23 Alexander M. Evidence-Based policy: a driving force in nursing regulation. Journal of Nursing Regulation 2020;11:3.

24 Bachtel MK, Hayes R, Nelson MA. The push to modernize nursing regulations during the pandemic. Nurs Outlook 2020;68:545-7.

25 Dileep Kumar T. Health and nursing policy, regulation and legislation, leadership and management. Int J Nurs Sci 2017;4:335.

26 Irena Ferreira D. Health and nursing policies, laws and regulations, governance and management, nursing leadership in Brazil. Int J Nurs Sci 2017:4:332.

27 Sarkisova V. Health and nursing policy, regulation and legislation, leadership and management. Int J Nurs Sci 2017;4:333-4.

28 Stievano A, Caruso R, Pittella F, et al. Shaping nursing profession regulation through history - a systematic review. Int Nurs Rev 2019;66:17-29.

29 Baumann A, Norman P, Blythe J, et al. Accountability: the challenge for medical and nursing regulators. Healthc Policy 2014;10:121-31.

30 Gross JM, Maureen K, Carey M. A model for advancing professional nursing regulation: the African health profession regulatory collaborative. J Nurs Regul 2015;6:29-33.

31 Gross JM, McCarthy CF, Verani AR, et al. Evaluation of the impact of the Arc program on national nursing and midwifery regulations, leadership, and organizational capacity in East, central, and southern Africa. BMC Health Serv Res 2018;18:406.

32 Uys LR. An investigation into the structure and functioning of nursing councils in South Africa. Curationis 1994;17:2-8.

33 Etikan I, Musa SA, Alkassim RS. Comparison of convenience sampling and purposive sampling. American Journal of Theoretical and Applied Statistics 2016;5:1-4.

34 Harris PA, Taylor R, Thielke R, et al. Research electronic data capture (REDCap)--a metadata-driven methodology and workflow process for providing translational research informatics support. J Biomed Inform 2009;42:377-81.

35 Dziuban CD, Shirkey EC. When is a correlation matrix appropriate for factor analysis? some decision rules. Psychol Bull 1974;81:358-61.

$36 \mathrm{Kim} \mathrm{J}-\mathrm{O}$, Mueller CW. Factor analysis: statistical methods and practical issues. Newbury, California: Sage, 1978.

37 Taber KS. The use of Cronbach's alpha when developing and reporting research instruments in science education. Res Sci Educ 2018;48:1273-96. 
38 Boateng GO, Neilands TB, Frongillo EA, et al. Best practices for developing and validating scales for health, social, and behavioral research: a primer. Frontiers in Public Health 2018;6:1-18.

39 Resnik DB, Shamoo AE. The Singapore statement on research integrity. Account Res 2011;18:71-5.

40 Salisu WJ, Sadooghiasl A, Yakubu I, et al. The experiences of nurses and midwives regarding nursing education in Ghana: a qualitative content analysis. Nurse Educ Today 2020;92:104507.

41 Blaauw D, Ditlopo P, Rispel LC. Nursing education reform in South Africa--lessons from a policy analysis study. Glob Health Action 2014;7:26401.

42 Flaskerud JH. Is the Likert scale format culturally biased? Nurs Res 1988;37:185-6.

43 Kinzie JD, Manson SM, Vinh DT, et al. Development and validation of a Vietnamese-language depression rating scale. Am J Psychiatry 1982;139:1276-81.

44 Armstrong SJ, Rispel LC. Social accountability and nursing education in South Africa. Glob Health Action 2015;8:27 879

45 Armstrong SJ, Geyer N-M, Bell CA. Capacity of South African nursing education institutions to meet healthcare demands: a looming disaster? Int J Afr Nurs Sci 2019;10:92-101.

46 Nursing \& Midwifery Council. Find an office near you: Nursing \& Midwifery Council, 2020. Available: https://www.nmc.gov.gh/web/ find-an-office-near-you

47 Nursing and Midwifery Council. 5-Year strategic plan (2015-2019. Nursing and Midwifery Council, 2015: 1-10.
48 Mtshali NG, Zwane ZP. Positioning public nursing colleges in South African higher education: Stakeholders' perspectives. Curationis 2019;42:1-11.

49 Govender S, Brysiewicz P, Bhengu B. Pre-licensure experiences of nurses performing compulsory community service in KwaZuluNatal, South Africa: a qualitative study. International Journal of Africa Nursing Sciences 2017;6:14-21.

50 Democratic Nursing Organisation of South Africa. DENOSA to lead nurses to a March to South African nursing Council and national department of health offices in Pretoria on 22 February 2017. Democratic Nursing Organisation of South Africa, 2017. https://www. denosa.org.za/Media View.php?id=35718

51 Bvumbwe T, Mtshali $\bar{N}$. Nursing education challenges and solutions in sub Saharan Africa: an integrative review. BMC Nurs 2018;17:3.

52 Shamian J. No health without a workforce, no workforce without nurses. Br J Nurs 2016;25:54-5.

53 South African Nursing Council. Response to the memorandum of demands from the Democratic nurses organisation of South Africa (DENOSA) to the South African nursing Council (SANC). South African Nursing Council, 2017. https://www.sanc.co.za/archive/ archive2017/newss1702.htm

54 Taber KS. The Use of Cronbach's Alpha When Developing and Reporting Research Instruments in Science Education. Res Sci Educ 2018;48:1273-96.

55 Ibrahim N, Shiratuddin MF, Wong KW. Instruments for measuring the influence of visual persuasion: validity and reliability tests. Eur. j. soc. sci. educ. res. 2015;4:25. 